\title{
DEMOCRACIA E IGUALDAD EN AMÉRICA LATINA $\left(^{*}\right)$
}

Desigualdades en América Latina: la posibilidad de la democracia.

mérica Latina sufre, desde 1981, la más grave crisis económica de la segunda
mitad de este siglo.
La crisis no sólo es persistente, sino también profunda y amplia.
Persistente, porque sus principales características y síntomas
permanecen hasta hoy, de modo que no se necesita ser siquiera muy pesimista para vaticinar que en muchas economías del continente el ingreso por habitante será menor en 1990 que en 1980. Por otra parte, en un muy reciente informe anual de la Comisión Económica para América latina (CEPAL), dado a conocer en Santiago (Chile) el 23 de septiembre de este año, se pronostican para 1988, en la mayoría de los países, indicadores económicos más desfavorables que los exhibidos en el curso de 1987.

La crisis es además profunda, porque se refleja en un empeoramiento serio de los mencionados indicadores económicos, tales como producción, empleo, remuneraciones y endeudamiento externo.

Y amplia -añadimos- por el alto número y variadas y diversas características de las economías de la región que han sufrido las consecuencias de la crisis. Con esto último se quiere decir que la crisis ha afectado tanto a economías grandes (Méjico, Brasil) como pequeñas (los países de América Central); a países exportadores de combustible (como Venezuela y Ecuador) y a naciones que dependen completamente de las importaciones para su abastecimiento de combustible (como Uruguay y Paraguay); a países que han aplicado políticas más intervencionistas (Perú) y a otros que han seguido el libre juego de las reglas del mercado (Chile).

Las dimensiones de esta crisis se harán ver todavía más fuertemente en el grave problema de la pobreza en el continente latinoamericano. Hoy puede estimarse en 130 millones de personas la cifra de quienes viven en condiciones de pobreza crítica en América Latina, lo cual equivale al $35 \%$ de la población total. En el año 2000, cerca de 170 millones de latinoamericanos continuarán viviendo en condiciones de pobreza crítica.

${ }^{(*)}$ Este trabajo, con algunas variantes, corresponde a la ponencia presentada en el Congreso «América Latina y Europa en Diálogo», que tuvo lugar en Münster desde el 28 de septiembre al 2 de octubre de 1987. 
Así, en ese año -ya no tan lejano- uno de cada cuatro habitantes urbanos será pobre, en tanto que el $50 \%$ de los habitantes rurales será pobre también. Con todo, la incidencia de la pobreza en relación a la población total habrá descendido en esa época a un $30 \%$.

Ahora bien, la disminución relativa de la pobreza crítica en el presente decenio y en el próximo, se estima que será menor que la experimentada en el decenio 1970-80. Así, mientras que entre 1970 y 1980 los cálculos muestran una reducción de la incidencia de la pobreza de $40 \%$ a $35 \%$, entre 1980 y el año 2000 dicha incidencia se reducirá sólo del $35 \%$ al $30 \%$.

Del modo indicado, los pronósticos acerca de un crecimiento económico insuficiente en los próximos años agudizará el problema de la pobreza y, por consiguiente, la situación de desigualdad que, en proporciones variables, muestran internamente los países latinoamericanos.

Mi pregunta, entonces, es si la democracia como forma de gobierno -reconquistada o en vías de ser reconquistada en la mayoría de los países del continente- podrá o no ayudar a una atenuación de las desigualdades materiales existentes al interior de nuestros países, o cuando menos, a morigerar el impacto adverso que en tal sentido está provocando la actual crisis económica. Con esta pregunta quiere explorarse acerca de si las estrategias orientadas a expandir el aparato productivo podrán o no llevarse a cabo haciéndose cargo, a la vez, de las actuales deficiencias distributivas que muestran las democracias latinoamericanas.

De acuerdo a lo que expresamos en la parte inicial de este trabajo, el pronóstico no puede ser ciertamente muy alentador, porque la falta de un adecuado crecimiento obstaculizará cualquier estrategia redistributiva por medio de intentar una satisfacción de las necesidades básicas de las distintas poblaciones. Este pronóstico puede a su vez verse agravado por la circunstancia de que los países de América Latina, en atención al servicio que vienen haciendo de la deuda externa, propenderán seguramente a una expansión de la actividad económica vinculada antes a las exportaciones que a la economía interna, con las consiguientes restricciones en materia de gasto público, empleo y consumo. Cabe anotar, por ejemplo, que las transferencias de recursos que han debido realizar los distintos países de América Latina entre 1982 y 1985 alcanzó al 4’2\% del producto del año, cifra que es el doble de las reparaciones de guerra que debió realizar Alemania a los países vencedores en la segunda guerra mundial. Sin embargo, y pese a este tremendo esfuerzo, los países deudores no alcanzaron a cubrir la mitad de los pagos de los intereses de la deuda correspondiente a la región.

Sin embargo, el problema de la redistribución de la riqueza y de la consiguiente atenuación de las desigualdades materiales al interior de cada país, no es un asunto que dependa únicamente de los niveles que pueda alcanzar el crecimiento económico en los diversos países, sino también de la voluntad política de los gobiernos democráticos en favor de la obtención en América Latina de sociedades más igualitarias, así como de los consensos que estos mismos gobiernos puedan conseguir en relación con esta finalidad. 
Decimos lo anterior porque en América Latina no parece haber existido antes una relación que pueda considerarse favorable entre crecimiento económico y disminución de las desigualdades materiales entre los distintos sectores de cada población, lo cual resulta expresivo de que las estructuras de poder han tenido también influencia en la estabilidad de condiciones distributivas no equitativas entre los diversos grupos sociales.

En efecto, entre 1960 y 1980, los dos decenios que corresponden a los de mayor crecimiento económico en América Latina, la duplicación en ese mismo período del producto bruto por habitante no trajo consigo, por ejemplo, una reducción de la incidencia de la pobreza en una proporción que pudiera considerarse similar. De este modo, entre 1960 y 1980, el producto bruto por habitante en América Latina, medido en dólares de 1970, aumentó de 550 a 1.000 , esto es, en un $84 \%$, en tanto que la incidencia de la pobreza se redujo sólo del $50 \%$ al $35 \%$, habiendo por otra parte aumentado, en términos absolutos, de 112 millones a 130 millones de personas. En consecuencia, se puede afirmar que los beneficios del crecimiento económico en ese período no se reflejaron de una manera proporcional en la reducción de la magnitud de la pobreza, y, por la inversa, la distribución del ingreso se hizo más desigual. El crecimiento económico, entonces, no se reflejó en efectos que puedan considerarse equitativos.

Hoy y mañana, por otra parte, con un menor crecimiento y, sobre todo, con un producto cuyo componente en expansión será seguramente el rubro exportaciones, con la consiguiente destinación de los mayores ingresos al servicio de la deuda y no a la satisfacción de las necesidades básicas, las dificultades para conseguir mayor equidad en las economías internas de nuestras sociedades serán todavía más acentuadas.

Sin embargo, si todo ello refuerza la posibilidad de que hacia finales de esta década, como también de la próxima, América Latina tenga sociedades aún más desiguales desde el punto de vista material, nos parece que, por otro lado, no tendría por qué descartarse una cierta influencia que en un sentido opuesto pueda tal vez hacer valer la democracia como forma de gobierno preponderante en el continente, dada -por una parte- la mayor permeabilidad de la democracia a la identificación y satisfacción de las llamadas necesidades básicas de la población, -y por otra- su mayor poder de negociación y de acuerdo en el plano internacional, tanto para obtener mejores fórmulas de servicio de la deuda, como para convenir pactos económicos regionales y subregionales que puedan colaborar a revertir, en alguna medida, los pronósticos poco alentadores que se formulan en la actualidad. Así, es sabido que ocho naciones de América Latina -todas con regímenes democráticos-, han constituido el llamado «Grupo de los 8 », destinado a encarar en conjunto el problema de la deuda, como también a abrir un camino -seguramente largo de recorrerpor el que pueda llegarse algún día al ansiado mercado común latinoamericano. Los presidentes de estos países se reunieron en Acapulco los días 27 y 28 de noviembre de 1987 y entre ellos no estuvieron los mandatarios de Chile y de Paraguay.

Desde luego que América Latina es una realidad heterogénea y que, sobre todo en materia económica, es ilusiorio proponer políticas que puedan llegar a tener una perfecta validez general en todos los países. 
Esta diversa realidad de las naciones del continente se aprecia, por ejemplo, en las diferencias del producto interno por habitante, que en algunos países es inferior a 800 dólares anuales (Bolivia), en otros oscila entre 1.000 y 1.400 dólares anuales (Perú, Ecuador), en tanto que otras naciones, que pueden ser calificadas de «mediano desarrollo» (Brasil y Argentina) se encuentran a este respecto en mejores condiciones. La diversidad se muestra también en la muy distinta incidencia de la pobreza y en la diferente proporción de indigentes que tiene cada país. En Brasil y Perú, por ejemplo, casi la mitad de los pobres son indigentes, en Colombia y Venezuela el 40\%, y en Argentina sólo el 10\%.

Por otra parte, en países como Argentina y Uruguay, el $40 \%$ más pobre de la población concentra aproximadamente entre el 14\% y el 19\% del ingreso total, mientras que en Chile este mismo segmento de la población logra participar apenas en el $10 \%$. Por otra parte, el desempleo urbano en 1980 era en Brasil del 3,8\%, en Argentina del 4,8\%, en Chile del 13,4\% y en Bolivia del 20\%. Habría que decir, también, que el deterioro de la situación ocupacional en América Latina ha ido de la mano con un aumento considerable de las diversas formas del subempleo. El caso extremo a este último respecto es el de Perú, donde entre 1980 y 1985 la tasa de desocupación abierta subió de 7\% a 10\%, mientras que la tasa de subocupación se elevó del $26 \%$ al $42,5 \%$.

Por otra parte, y desde el punto de vista político, la reposición de la democracia en algunos países muestra también la heterogeneidad de nuestras naciones, puesto que tal reposición no ha tenido lugar simultáneamente, ni por unas mismas causas ni en similares condiciones de estabilidad futura en todos los países.

Sin embargo, el desafío consiste -según nos parece- en utilizar la democracia no sólo para obtener su propia consolidación como forma de gobierno, así como el reforzamiento consiguiente del régimen de libertades que ella supone -lo cual es, por sí solo, toda una tarea-, sino también para propender con gradualidad, aunque también con persistencia -algo así como la tesis de Bobbio de «un paso a la vez»-, a una atenuación de las desigualdades materiales más evidentes e injustas que se muestran hoy, en distintas proporciones, según hemos visto, en las naciones de nuestro atribulado continente.

Se trata, como puede verse, del tema de la relación entre democracia e igualdad, el cual supone, como es obvio, que esclarezcamos a continuación qué entendemos por democracia y por igualdad, para establecer luego si es posible suscribir como una exigencia, y asimismo como una posibilidad, que desde la democracia se marche deliberadamente en pos de metas igualitarias, cuyos logros no signifiquen, por cierto, que la democracia deba pagar el precio del sacrificio de la libertad; un precio demasiado alto, en verdad, que la democracia no puede nunca pagar sin dejar de ser ella misma.

\section{Una noción procedimental de democracia.}

La palabra «democracia» suele ser empleada en diversos sentidos.

En primer término, se la utiliza, frecuentemente, para aludir a una 
determinada forma de gobierno, y es en este sentido, precisamente, del que tratarán de la democracia las páginas que siguen de esta ponencia.

Se usa también la palabra «democracia» para designar no ya una determinada forma de gobierno, sino un cierto contenido de un orden social y económico a ser instaurado desde el gobierno, concretamente de un orden que, al privilegiar la igualdad por sobre la libertad de los individuos, tiene por finalidad la nivelación de las desigualdades resultantes de las diferencias de clase. De acuerdo a este uso, el término «democracia» adquiere un sentido más económico que político y se asocia, además, al concepto de economía planificada.

Todavía, y sobre todo en el lenguaje común de las personas, la palabra «democracia» es empleada para referirse a algo todavía más general: a una determinada actitud o forma de vida, en la que se combinan hábitos tales como el respeto a la personalidad e ideas de los demás, la disposición a escuchar y atender razones, la crítica y la autocrítica, la intención persuasiva antes que el afán de imponerse, la tendencia a la búsqueda de soluciones convenidas que articulen el mayor número de intereses, la duda sobre los puntos de vista propios y, aún, un cierto sentimiento de culpa y de falibilidad.

En lo que sigue nos vamos a referir a la democracia política, esto es, a la democracia como forma de gobierno, como modo de organizar la adopción de las decisiones colectivas, sentido éste en el que la democracia responde a dos cuestiones fundamentales que se plantean en toda comunidad: quiénes y cómo deben gobernar. Ya veremos, sin embargo, que si la democracia responde a estas dos preguntas, lo hace de una manera puramente procedimental.

Por otra parte, si resulta necesario plantearse las dos preguntas antes enunciadas, a saber, quién y cómo debe gobernar, no es ello simplemente -como cree Popper- porque en el fondo de ambas interrogaciones palpite un germen autoritario, en el sentido de que sólo quienes quieren tener una autoridad sobre sí pueden razonablemente preguntarse acerca de quién deba ser dicha autoridad y cómo deba proceder ésta en las cuestiones de gobierno. Nos parece, en cambio, que lo que conduce inevitablemente a esas dos preguntas, y a la búsqueda de las respuestas correspondientes, es el hecho de vivir en sociedad, y -como acontece hoy- en sociedades extensas y complejas. Extensas, por el alto número de individuos que las componen; y complejas, porque al interior de toda comunidad concurren ideas e intereses múltiples y diversos, cuando no francamente contrapuestos entre sí. Es ese doble carácter de nuestras sociedades, entonces -el de ser plurales y a la vez pluralistas-, lo que conduce a la pregunta acerca de quiénes y cómo deberán adoptar las decisiones de interés común.

Tiene razón, pues, Berlin cuando en su conocida conferencia sobre Dos conceptos de libertad, apunta que «si los hombres no hubieran estado en desacuerdo sobre la finalidad de la vida y nuestros antepasados hubiesen seguido imperturbables en el Jardín del Edén, apenas pudieran haber sido concebidos los estudios a los que está dedicada la cátedra de teoría política y social», puesto que tales estudios -concluye el autor- «tienen su origen y se desarrollan en la existencia de la discordia». 
La contribución a la teoría democrática de parte de algunos de los más destacados juristas del presente siglo, como Hans Kelsen, Alf Ross y Norberto Bobbio, nos facilita la afirmación acerca de que la idea tradicional y comúnmente convenida en nuestro tiempo de la democracia política, presenta a ésta como una forma de gobierno en la que el poder político, o sea, la soberanía, esto es, la facultad de tomar decisiones colectivas, pertenece en derecho a la población adulta toda y no meramente a un individuo singular o a un grupo específico y limitado de gente. El poder político -decimos-, o sea, lo que captamos de él, esto es, los actos de autoridad en que este mismo poder se expresa, a saber, actos legislativos, actos de la administración y decisiones de orden jurisdiccional.

Ahora bien, ¿que quiere decir que el poder político se encuentre radicado en el pueblo en su totalidad, puesto que es claro que el pueblo, en cuanto tal, no establece directamente el contenido de las leyes, ni emite tampoco los actos administrativos ni procede, por último, al conocimiento y fallo de los asuntos jurídicamente relevantes que se promueven en el curso de la vida social?

Podemos decir que se considerará que el poder descansa en el pueblo si el o los órganos de gobierno que establecen el contenido de la voluntad nacional en su forma suprema y más general, es o han sido instituidos como representantes del pueblo. Ahora bien, para que los órganos supremos del Estado puedan ser tenidos como representantes del pueblo, se requiere, desde luego, como condición básica, la existencia de elecciones periódicas, amplias, libres e informadas, porque nadie que se diga representante del pueblo lleva en tal sentido una marca en la frente ni cosa que se le parezca. Sólo un sistema tal de elecciones puede asegurar grados reales y aceptables de representatividad de quienes se instalen temporalmente en el poder público, aunque, por lo mismo, tratándose de una democracia, lo único que puede decirse es que el poder deriva del pueblo, aunque no es ejercido directamente por el pueblo.

Así entendida, la democracia resulta ser un método de adopción de las decisiones colectivas, que puede conducir, en consecuencia, a distintos contenidos para esas mismas decisiones, esto es, a diversos órdenes sociales y económicos. Democracia es entonces un procedimiento, un conjunto de reglas, a través de las cuales se opta por un programa social y económico, y no el contenido de un determinado orden social y económico que se considere de antemano como el mejor o el más justo.

$\mathrm{Si}$, pues, a fin de cuentas, la democracia política es un procedimiento de toma de decisiones, esto es, un método para determinar la voluntad de la mayoría, el concepto de democracia nada nos dice directamente acerca del contenido efectivo que pueda ser luego instaurado y desarrollado con este método. Como apunta Alf Ross, «la democracia indica un cómo, no un qué. Apunta, por tanto, a la manera como se efectúan las decisiones políticas y no tiene que ver con algún determinado contenido de estas mismas decisiones». «La democracia -insiste el autor escandinavo- es sólo un método político, una supraideología, y no una norma material relativa al sistema de las condiciones sociales». 
Esta definición formal de democracia se contrapone -como explica ahora Bobbioa la definición sustancial de democracia. Esta última define la democracia por referencia al contenido de las decisiones que, de acuerdo con determinados valores, deberían adoptarse por el gobierno.

La distinción entre concepción formal y concepción sustancial de democracia -sigue nuevamente Bobbio- «corresponde a la misma distinción que efectuaban los escritores franceses del siglo pasado entre «democratie par le peuple» y «democratie pour le peuple». La definición procedimental que hemos adoptado aquí es la primera: «par le peuple». La definición sustancial es la segunda: «pour le peuple».

Pensamos que Bobbio tiene razón cuando insiste acerca de la necesidad de distinguir entre ambos conceptos de democracia, porque ambas definiciones de democracia pueden perfectamente no coincidir en la realidad de un régimen democrático dado. Puede existir una democracia formal «par le peuple» que no sea del todo «pour le peuple», como ocurre cuando adquiere preeminencia un partido conservador, por ejemplo. Pero también puede haber democracia «pour le peuple» que no sea «par le peuple», como es esa pretendida democracia que se realiza actualmente en países del este europeo y que sus partidarios llaman «democracia popular».

En consecuencia, si la democracia responde a las preguntas de quién y como debe gobernar, lo es sólo de una manera formal o -como se dijo antes- «procedimental». Debe gobernar no alguien determinado de antemano, sino cualquiera que obtenga para sí la mayoría. Y en cuanto a cómo debe gobernarse, la democracia establece únicamente las reglas y procedimientos que deben ser observados en la adopción de las decisiones colectivas, aunque no determina el contenido de estas decisiones. El contenido será, en cada caso, el que corresponda al programa de gobierno que cuente con el apoyo de la mayoría. En este sentido, ser demócrata no es otra cosa que estar dispuesto a entrar periódicamente en lucha de ideas con los demás acerca del mejor o más conveniente orden social y estar dispuesto también a entregar el poder, por un tiempo previamente establecido, a quien obtenga para sí la mayoría.

Además, la idea de democracia se relaciona no con la imposición de un solo punto de vista acerca de cuáles deban ser las condiciones sociales o económicas que deberán prevalecer, aunque éste sea el punto de vista de la mayoría, sino con la concurrencia, debate, compromiso y transacción entre los grupos o puntos de vista opuestos, lo cual supone, por cierto, que éstos se organicen en partidos políticos.

Por lo mismo, el valor del debate que promueve la democracia, que no es sino, en el fondo, el debate que se libra entre las ideas y los intereses opuestos de los mismos grupos y partidos que intervienen en la discusión, no se encuentra propiamente en que ese debate pueda «constituir un camino hacia la verdad a través de la combinación de argumentos, sino -como dice Ross- en ser un camino hacia el compromiso».

Max Weber escribió alguna vez que «la empresa política es una empresa de interesados». Por lo mismo, y en cuanto a que la democracia no busca establecer una verdad en punto a cuáles ideas o intereses son 
los mejores, sino tan sólo un acuerdo o compensación entre ellos, Raymond Aron ha podido decir de la democracia que, en el fondo, «es el único régimen que confiesa que la historia de los Estados está y debe estar escrita en prosa y no en verso».

Por lo mismo, nos parece que tiene mucha razón el protagonista del libro El nombre de la rosa, Guillermo, el monje benedictino que se caracterizaba «por expresar sus certezas de una manera tan dubitativa», cuando nos propone que «la única verdad consiste en aprender a liberarnos de la insana pasión por la verdad», lo cual valdría, sobre todo, en política, y que -como aconseja luego el mismo Guillermo- habría que huir de los que están dispuestos a morir por la verdad (o sea, los que no están dispuestos a negociar y a transar con los demás), «porque suelen provocar también la muerte de muchos otros, y a menudo antes que la propia y a veces en lugar de la propia».

A esto es a lo que hemos llamado una definición «procedimental» de democracia, o «definición mínima», como la llama por su parte Norberto Bobbio.

\section{Democracia y libertad.}

Por lo que se refiere al problema de la libertad y al de la relación de ésta con la democracia, y siguiendo en esto a Ross y a Bobbio, podemos constatar -por una parte- que ciertas libertades son indispensables para el ejercicio del poder democrático, en el sentido de que están ellas indisolublemente ligadas a la democracia como forma de gobierno, puesto que sin esas libertades el principio o regla de la mayoría perdería todo su sentido, y -por otra- que la democracia es también la forma de gobierno que ofrece mejores condiciones para la protección y consiguiente subsistencia de esas mismas libertades.

Así, Bobbio, en uno de sus últimos libros -El futuro de la democracia-, sostiene que el Estado liberal es el presupuesto no sólo histórico, sino también jurídico del Estado democrático. Estado liberal y Estado democrático -sigue el autor italiano- son interdependientes de dos formas: en la dirección que va desde el liberalismo hasta la democracia, en el sentido de que se necesitan ciertas libertades para el correcto ejercicio del poder democrático, y en la dirección opuesta, que va desde la democracia hasta el liberalismo, en el sentido de que se necesita el poder democrático para garantizar la existencia y persistencia de las libertades fundamentales», tales como la libertad de pensamiento, expresión, reunión, asociación y, por cierto, la misma libertad política, esto es, el derecho a una participación activa en la adopción de las decisiones colectivas.

Por todo lo dicho, y -sobre todo- porque la democracia se erige, por así decirlo, sobre un andamiaje de libertades, cuya subsistencia, por otra parte, la propia democracia protege y garantiza permitiendo así que estas libertades pervivan y se desarrollen como tales, todo aquel que, por ello, dé valor a la libertad y, en concreto, a las libertades antes señaladas y las considere -como dice Ross- «un bien indispensable, personal y 
humano», tiene más que buenas razones para preferir la democracia como forma de gobierno.

Digamos también que la garantía y protección de la libertad se consigue en una democracia, especialmente, por medio de las llamadas «declaraciones de derechos», que, por cierto, limitan el poder de las mayorías en el gobierno. En otras palabras: de acuerdo al principio democrático se cree que la mayoría debe gobernar, pero, al mismo tiempo, se entiende que debe limitarse el poder de la mayoría, y para ello se recurre a las restricciones constitucionales que introducen las declaraciones de derechos.

Como expresa Leonard W. Levy, Premio Pulitzer en 1969, «creemos en la autodeterminación regida por el gobierno de la mayoría y creemos también en las limitaciones al gobierno de la mayoría. Esta paradoja se aclara -dice en seguida el autor norteamericano- si nos fijamos en que la finalidad que persiguen tanto la autodeterminación como las limitaciones impuestas al gobierno de la mayoría es la misma: garantizar la libertad».

\section{Democracia e igualdad.}

Como apunta Ross, «si bien la relación de la democracia con la idea de libertad es clara y directa, la situación es muy diferente en lo que hace a la idea de igualdad».

Tanto es así que existe incluso la idea -harto difundida- de que estos dos valores -libertad e igualdad- se repelerían entre sí, y que, por lo mismo, las sociedades, y dentro de éstas los individuos que las componen, estarían colocados fatalmente ante la opción de escoger la libertad con sacrificio de la igualdad, o bien preferir la igualdad teniendo que inmolar en tal caso las libertades que mencionamos hace un instante.

Quizá sí la experiencia histórica de las sociedades capitalistas haya favorecido la idea de que la libertad se consigue al precio de provocar, mantener, y en ocasiones incluso agudizar, las desigualdades materiales existentes entre los hombres, como por su parte las sociedades socialistas que conocemos hayan seguramente estimulado la convicción acerca de que niveles aceptables de igualdad sólo pueden ser conseguidos al precio de tener que sacrificar la libertad.

Por nuestra parte, y sin desconocer las fricciones entre libertad e igualdad, y, sobre todo, las dificultades que encontrará siempre todo programa y acción políticos que intente avanzar hacia una sociedad más igualitaria conservando el régimen de libertades y la democracia que las hace posibles, me parece que ambos puntos de vista -tanto el que desecha la igualdad en nombre de la libertad como el que desprecia el régimen de libertades llamadas «formales» en aras de obtener una mayor igualación social y económica de las personas- simplifican un tanto las cosas, porque pensamos que no se puede desechar de plano el intento de conciliar, dentro de ciertos límites, libertad con igualdad, lo mismo que se hace, por ejemplo, entre libertad y orden.

¿Se repelen orden y libertad? 
En cierto punto, sí; pero creo que nadie aceptaría sensatamente hoy la idea de que para tener orden es preciso sacrificar la libertad, como tampoco parece aceptable la idea de que todo orden debe ser rechazado en nombre de la libertad.

Precisamente, el desafío consiste en armonizar orden con libertad, y en advertir que hay una buena dosis de irresponsabilidad política, y hasta de inexcusable simpleza, tanto en la doctrina de quienes desearían sacrificar cándidamente el orden a la libertad, cuanto en la de quienes, presas del terror a la desintegración social y a la falta de autoridad y de dirección, propugnan el sacrificio inverso, esto es, sofocar al máximo las libertades para conseguir así un mínimo de orden.

Me pregunto, entonces, si acaso la relación libertad-igualdad no debería ser planteada de la misma manera, sobre todo si por igualdad se entiende no la supresión de toda diferencia -lo cual constituiría una evidente falta de realismo-, sino, al modo como lo expresa Bobbio, tan sólo la aproximación gradual, pero sostenida, a una «sociedad más igualitaria que las que hemos conocido y conseguido realizar hasta ahora».

«El liberalismo -escribe Bobbio- se inspiró sobre todo en el ideal de libertad. Pero es inútil ocultarnos que la libertad de iniciativa económica ha creado enormes desigualdades no sólo entre hombre y hombre, sino también entre Estado y Estado».

Por lo mismo, parece pertinente demandar de la democracia no sólo la preservación del régimen de libertades que la hacen posible, sino también una voluntad igualitaria, en el sentido de emplear el poder del Estado para atenuar las desigualdades manifiestas e injustas, cuya agudización, por otra parte, puede tornar enteramente ilusorio y vacío, para mucha gente, el disfrute y ejercicio de las libertades públicas. Es evidente, por cierto, que el método democrático, en relación al problema de la disminución de las desigualdades materiales y a la sustitución o reemplazo del tipo de sociedad que más favorece esas mismas desigualdades, es sólo capaz de pequeños y graduales pasos de cantidad, aunque no debe ignorarse -como recuerda Bobbio- «que una ley de la dialéctica consagrada por Engels dice que la cantidad, a la larga, se transforma en calidad».

Sin embargo, habría que recordar que es el valor de la libertad, y no el de la igualdad, el que define en primer lugar a la democracia como forma de gobierno. La misma idea de libertad, incluso, es independiente de la de igualdad, salvo de la de igualdad para la titularidad y ejercicio de la libertad (igualdad política).

Por lo mismo, el problema se plantea en relación con la igualdad material, aunque debe tenerse presente que cuando hablamos aquí de igualdad lo que nos proponemos no es la supresión de toda diferencia -una sociedad enteramente uniforme sería en verdad intolerable-, sino tan sólo la disminución o eliminación de las diferencias más graves o injustas.

Por lo mismo, y empleando aquí el lenguaje de Kelsen, no se trata de emplazar bajo el nombre de «democracia» la ideología de la igualdad, o bien de la justicia, dejando de lado la ideología de la libertad, 
sino, como se ha venido diciendo antes en esta misma ponencia, de mantener el ligamen libertad-democracia, aunque demandando de ésta una política económica y social que cautelando la integridad / pervivencia de ese vínculo en lo que tiene de más sustancial, permita avanzar, gradual pero sostenidamente -como fue dicho antes también- a una sociedad más igualitaria que las que hemos conseguido realiza hasta ahora.

Por lo mismo, la mayor igualdad que a nuestro entender podría legítimamente demandarse de un régimen democrático sin poner seriamente en peligro las libertades que lo sustentan y que ese mismo régimen tiene el compromiso y el deber de garantizar y de proteger, no puede ser nunca una igualdad regimental, esto es, impuesta, sino una igualdad buscada trabajosamente, o sea, imaginativamente, a través del propio ejercicio de la libertad, en cuanto este ejercicio no tenga sólo en cuenta las ideas e intereses de cada cual, sino también la persona, las ideas y los intereses del otro, de los demás, con lo cual la libertad no sólo puede ser mantenida, sino que -además- se torna solidaria, esto es, se humaniza.

Por tanto, y a pesar de su indesmentible resonancia utópica, quizá no esté del todo desacertado el viejo lema revolucionario: libertad, igualdad, fraternidad. Tal vez la fraternidad, esto es, la unión y buena correspondencia entre los que lo son o a lo menos se tratan como hermanos, pueda constituir el puente que se necesita tender entre los valores de la libertad y de la igualdad, a fin de que, reconociéndose distintos, no se repelan, y propendan, en cambio, junto con preservar sus respectivas autonomías, a ceder cada cual de sí en la proporción justa que permita la realización simultánea del otro.

«Nunca dejará de haber pobres sobre la tierra», admite uno de los libros del Antiguo Testamento. Sin embargo, lo que se concluye en este texto no es que se deba endurecer el corazón ante los más necesitados, sino todo lo contrario. «Por eso -sigue el Deuteronomiote doy este mandato: abrirás tu mano a tu hermano, al necesitado y al pobre de tu tierra».

Por otra parte, es evidente que para propender a sociedades más igualitarias y, en especial, para conseguir que el crecimiento beneficie en cada país proporcionalmente más a los pobres, se requiere -al parecer inevitablemente- de un cierto grado de intervención de la autoridad pública.

Mario Vargas Llosa, en el Prólogo a un libro de aparición reciente en el Perú, junto con defender el principio de libertad en materia económica -a la que considera como «la contrapartida de la libertad política...»- admite, con todo, que «es natural que en un país del tercer mundo, con las desigualdades económicas, la falta de integración cultural y los problemas sociales..., el Estado tenga una función redistributiva que cumplir». Sin embargo, el mismo autor sostiene con énfasis -por otra parte- que lo fundamental es que el «Estado recuerde siempre que, antes de redistribuir la riqueza, hay que producirla».

Se trata, por cierto, de una elección elemental, siempre que se recuerde, también -lo cual Vargas Llosa parece olvidar- que no parece 
justo, ni tampoco muy realista, esperar a que la riqueza se acumule para empezar a preocuparse de redistribuirla dentro de ciertos márgenes, o para aguardar algo todavía más ilusorio: que la riqueza acumulada rebalse por sí sola hacia los más pobres. La riqueza no es centrífuga. Tiende por el contrario, junto con crecer, a concentrarse. Y aunque se compartiera la ensoñación de que el crecimiento de la riqueza garantiza por sí solo, a la larga, una mejor distribución de ésta, lo cierto es que el tiempo que ello demandaría, en presencia, sobre todo, de un Estado excesivamente abstencionista, importaría la condena de una o varias generaciones a un grado ciertamente inaceptable de paciencia social. Los padres de hoy no pueden ciertamente calmar el hambre de sus hijos, y ni siquiera consolarlos, con el vaticinio de que probablemente sus nietos podrán comer lo suficiente.

Por otra parte -y siguiendo en esto a Kriele-, quizá convendría recordar que sólo una «economía planificada» -en la que se elimina el mecanismo del mercado y en su lugar el Estado formula un plan económico total cuya ejecución es controlada por un aparato burocrático- es incompatible con la democracia y con el régimen de libertades que ésta supone como forma de gobierno. La «planificación económica», en cambio, que parte del sistema de mercado, pero que aprovecha simultáneamente en forma sistemática y deliberada las numerosas posibilidades -necesidades- de dirigir, limitar y controlar el mercado, es por su parte perfectamente compatible con los derechos fundamentales de las personas.

\section{Una conclusión.}

Así las cosas, y sin considerar que libertad e igualdad sean valores propiamente inseparables, nos parece que si bien es el primero de tales valores el que define ante todo a la democracia como forma de gobierno, ello no tiene por qué ser presentado, sin embargo, al modo de un obstáculo insuperable que impediría, o tornaría ilegítima, toda demanda o exigencia a la democracia en orden a obtener sociedades más igualitarias que las que hemos conseguido realizar hasta ahora en América Latina.

Por lo mismo, cabe preguntarse entonces si acaso la relación libertad-igualdad, que algunos consideran como valores inseparables (de modo que no habría propiamente libertad sin igualdad ni igualdad sin libertad), en tanto otros los estiman como valores que se repelen (de manera que habría que optar fatalmente entre ser libres o ser iguales), no debería ser planteada de otro modo, a saber, con clara conciencia de que se trata, en efecto, de valores distintos que pueden, en un cierto punto, colisionar entre sí, y, además, con igualmente clara voluntad de entender que es posible y necesario caminar desde la democracia, deliberada y gradualmente, hacia la obtención de modalidades más igualitarias de convivencia social y económica, aunque sin sacrificar el régimen de libertades -soporte de la democracia- de una manera que comprometa verdaderamente su existencia y funcionamiento. 
En consecuencia, se trata de que a través de la democracia protejamos nuestra libertad, aunque sin perder de vista lo que se esconde tras la pregunta que el Presidente argentino, Raúl Alfonsín, dirigió recientemente a Francois Mitterand, con motivo de la reciente visita de éste al país limítrofe: «¿cuánta pobreza puede soportar la libertad?».

Conciliar libertad e igualdad es, ciertamente, un camino erizado de dificultades, sobre todo para la libertad. Pero la actitud del buen demócrata -como dice Bobbio- tiene que ser la de «no hacerse ilusiones respecto a lo mejor», pero, a la vez, la de «no resignarse a lo peor».

Ahora bien, si una propuesta semejante debe ser calificada de «liberal-socialismo», o de «socialismo liberal», o de «liberalismo con justicia social», o -escuetamente- de «social democracia», poco importa en verdad. De lo que se trata, en todo caso, es de no aceptar una contradicción absoluta e irreductible entre libertad e igualdad, y de que, en consecuencia, la democracia se adopte no sólo como expresión y garantía de la primera, sino también como un instrumento de consenso en favor de una atenuación y eliminación de las diferencias más graves e injustas entre los hombres.

\section{BIBLIOGRAFÍA CONSULTADA}

1 «La pobreza en América Latina: dimensiones políticas», colección de Estudios e Informes de la CEPAL, Santiago, 1985.

2 "América Latina: crisis económica y ajuste externo», de Andrés Bianchi, en «Estudios Públicos», n. ${ }^{\circ}$ 24, Santiago, 1986.

3 «Dos conceptos de libertad», en «Libertad y necesidad en la historia», de Isaiah Berlín, Revista de Occidente, Madrid, 1974, traducción de Julio Bayón.

4 «Fundamento y futuro de la democracia», de Norberto Bobbio, Edeval, Valparaíso, 1986, traducción de Gabriel Del Favero.

5 «QQué socialismo?», de Norberto Bobbio, Plaza Janés, Barcelona, 1977, traducción de Juan Moreno.

6 «Esencia y valor de la democracia», de Hans Kelsen, Guadarrama, Madrid, 1977, traducción de Rafael Luego Tapia y Luis Legaz Lacambra.

7 «Why democracy?», de Alf Ross, Harvard University Press, 1952, traducción (no publicada) de Roberto J. Vernengo.

9 «Prólogo» a Hernando de Soto, «El otro sendero», de Mario Vargas Llosa, Editorial El Barranco, Lima, 1986.

10 «Introducción a la teoría del Estado», de Martin Kriele, Depalma, Buenos Aires, 1980, traducción de Eugenio Bulygin.

11 «Capitalización de la deuda, ¿la solución del problema?, entrevista al economista Felipe Larraín, «El Mercurio», Santiago, 25 de octubre de 1987.

12 «El futuro de la democracia», de Norberto Bobbio, Plaza-Janés, Barcelona, traducción de Juan Moreno, 1985. 